\begin{tabular}{l} 
Sharif University of Technology \\
Scientia Iranica \\
SCIENTIA \\
IRAN \\
Thansactions A: Civil Engineering \\
\hline
\end{tabular}

\title{
Water reducing agent effects on the engineering performance of cement stabilized aggregates
}

\author{
L. $\mathrm{Hu}^{\mathrm{a}, *}$, Zh. Liu ${ }^{\mathrm{a}}$, and A. Sha ${ }^{\mathrm{a}, \mathrm{b}}$ \\ a. School of Highway, Chang'an University, Xi'an 710064, P.R. China. \\ b. Key Laboratory of Special Area Highway Engineering of the Ministry of Education, Xi'an 710064, P.R. China. \\ Received 18 February 2016; received in revised form 7 January 2017; accepted 24 April 2017
}

\author{
KEYWORDS \\ Cement Stabilized \\ Aggregates (CSAs); \\ Water Reducing \\ Agents (WRAs); \\ Mechanical behavior; \\ Vibration compaction \\ method.
}

\begin{abstract}
Water Reducing Agents (WRAs) are usually utilized in cement concrete to reduce the water-cement ratio, increase mechanical strength, and improve the durability of concrete structures. As a kind of widely used construction materials in pavement structures, i.e., base or subbase courses, Cement Stabilized Aggregates (CSAs) have their own shortcomings, e.g., drying shrinkage at early ages. To evaluate the feasibility of water reducing agent in cement stabilized aggregates, and its effects on engineering performance, six groups of cement stabilized aggregates were prepared (water reducing content $=0,0.5$, 1.0, 1.5, 2.0, and 2.5 wt.\%). Engineering performances including density-water relationship, Unconfined Compressive Strength (UCS), Tensile Splitting Strength (TSS), Compressive Resilience Modulus (CRM), and Drying Shrinkage Strain (DSS) were measured. The results indicate that water reducing agents used in this study can significantly benefit the engineering performances of cement stabilized aggregates. The function of water reducing agent in cement stabilized aggregates is summarized in this paper, which would be beneficial to guide the water reducing agent utilization in cement stabilized aggregates.
\end{abstract}

(C) 2018 Sharif University of Technology. All rights reserved.

\section{Introduction}

Admixtures have been reported as the significant fifth component in cement concrete $[1,2]$, which play a very important role in cement-based composites. Among them, Water Reducing Agents (WRAs) may be the mostly used admixture in civil engineering, because WRAs can effectively reduce water usage in concrete, improving its engineering performance. Generally, to achieve a good workability of concrete, sufficient water is added to concrete mixtures, but excess water does

*. Corresponding author. Tel.: +86135 71898817

E-mail addresses: hlq123@126.com (L. Hu);

liuzhuangzhuang1986@gmail.com (Zh. Liu);

ams@chd.edu.cn (A.Sha)

doi: $10.24200 /$ sci.2017.4213 harm to the engineering performance of concrete or structures due to the water evaporation paths [3]. Thus, the function of WRAs in improving the engineering performance of concretes, e.g., High-Strength Concrete (HSC), Engineered Cementitious Composite (ECC), Green High Durable Concrete (GHDC), etc., has been reported in many publications $[2,4,5]$.

Cement Stabilized Aggregates (CSAs) are special composites bonded to the cementitious material. Due to its high mechanical performance and low cost [6], CSA has been widely used in course base all over the world [7-10]. Based on the current design methods of CSAs, the functions of water, whose content is determined by compaction capacity, are believed to be as:

i) Reactive component with cement during hydration;

ii) Solution in mixtures to ensure the compaction capacity during construction. 
In general, the usage of cement and water in CSA mixtures is about $4 \sim 5$ wt. $\%$ and $5 \sim 6$ wt. $\%$, respectively. From the viewpoint of cementitious materials, the water-cement ratio in CSAs might be $80 \% \sim 150 \%$, which is much higher than that in cement concrete. Actually, the real reacted water in Portland cement paste is only about $42 \%(w / c=0.42)$. Indeed, caused by much lower cement usage (4 5\%), much higher water-cement ratio $(80 \sim 150 \%)$, and different compaction technique (rolling), CSAs have to face many problems, the main one of which is drying shrinkage brought by sufficient water evaporation at early ages. Therefore, drying shrinkage in semi-rigid base course brings great risk of bottom-up cracking to asphalt pavement surface. Hence, the strategy of using WRAs to mitigate the drying shrinkage in CSAs at early ages seems feasible [11], and the roles of WRAs in cement stabilized aggregates are worth being studied.

This paper aims to reveal the functions of Water Reducing Agents (WRAs) in Cement Stabilized Aggregates (CSAs) based on evaluation of the engineering performance. Thus, six groups of CSA mixtures were prepared and then, Unconfined Compressive Strength (UCS), Tensile Splitting Strength (TSS), Compressive Resilience Modulus (CRM), and Drying Shrinkage Strain (DSS) were measured in laboratory. This study highlights the role of WRAs in CSAs. The conclusion and findings obtained would be helpful to improve the engineering performance of semi-rigid base course of asphalt pavements.

\section{Experimental program}

\subsection{Raw materials}

The aggregate used in this study was crushed limestone with a crushing value index of $25 \%$, produced by Stone Material Plant in Jingyang County, Shaanxi Province. Common Portland cement was supplied by Qingling Cement Company, Shaanxi Province. The cement was classified as PO42.5 according to the China's national standard of "Common Portland Cement" (GB 175-2007), with characteristics of fineness $(>80 \mu \mathrm{m})$ $=7.2 \%$, initial setting time $=2.54 \mathrm{~h}$, final setting time $=3.30 \mathrm{~h}$, compressive strength $(3 \mathrm{~d})=26.8 \mathrm{MPa}$, and flexural strength $=5.30 \mathrm{MPa}$. A commercial WRA (poly-carboxylic acid) was supplied by Main-horn Tech. with solid content $=33.3 \%, \mathrm{pH}$ value $=6.2$, and specific gravity $=1.14 \%$, according to the producer.

\subsection{Cement stabilized aggregate mixtures and proportioning}

The gradation of Cement Stabilized Aggregates (CSAs) mixture used in this study is detailed in Figure 1. It is one of the most ordinary types of CSAs for application in China. The aggregate mixtures were well designed according to China's national specification of "JTG

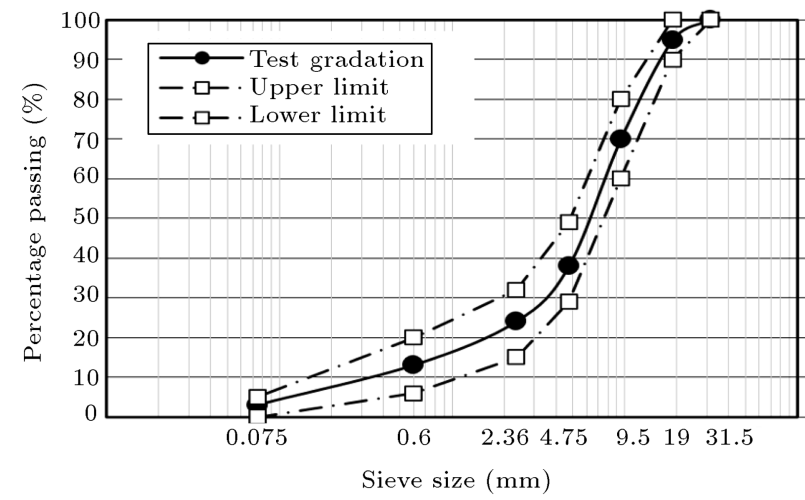

Figure 1. Gradation of the cement stabilized aggregate mixtures.

D50-2006" [12], in which the upper limit and lower limit were required, and the used gradation was in the mid-specification range. The cement content in CSAs was given as $4.5 \%$ of the total weight of mixtures. To evaluate the function of the Water Reducing Agent (WRA) in CSAs, several contents of WRA (0, 0.5, 1.0, $1.5,2.0$, and $2.5 \%$ of cement binder weight) were added to mixtures, and the Optimum Water Content (OWC) of each in CSAs was determined based on maximum density method $[13,14]$. More details of determination of OWCs will be provided in Section 3.

\subsection{Test methods}

To simulate the field construction technique, vertical vibration strategy was utilized in laboratory. The compacting machine and schematic diagram are shown in Figure 2. The static pressure of the vibration compactor was $104 \mathrm{kPa}$, vibration frequency was $28 \mathrm{~Hz}$, and vibrating force was set to $6.8 \sim 6.9 \mathrm{KN}$.

Cement stabilized aggregate mixtures were mixed and, then, moved into steel molds. Here, the mixtures should be compacted within 1 hour after mixing due to the cement hydration. The relative compaction of test specimens was given as $98 \%$.

Based on the OWCs, CSA samples were prepared for engineering performance measurements. All specimens used in this paper were sealed in plastic bags and stored in a curing chamber with a temperature of $20 \pm 0.5^{\circ} \mathrm{C}$ and relative humidity above $95 \%$. Before the measurement, specimens were soaked in room-temperature water for $24 \mathrm{~h}$. Engineering performances, i.e., Tensile Splitting Strength (TSS), Unconfined Compressive Strength (UCS), Compressive Resilience Modulus (CRM), and Drying Shrinkage Strain (DSS), were mainly measured complying with JTG E51-2009 [15]. In UCS test, cylindrical samples ( $\varnothing=150 \mathrm{~mm}, h=150 \mathrm{~mm}$ ) were measured. Then, the unconfined compressive strength was calculated according to Eqs. (1) and (2).

$$
\mathrm{UCS}=P_{u} / A
$$



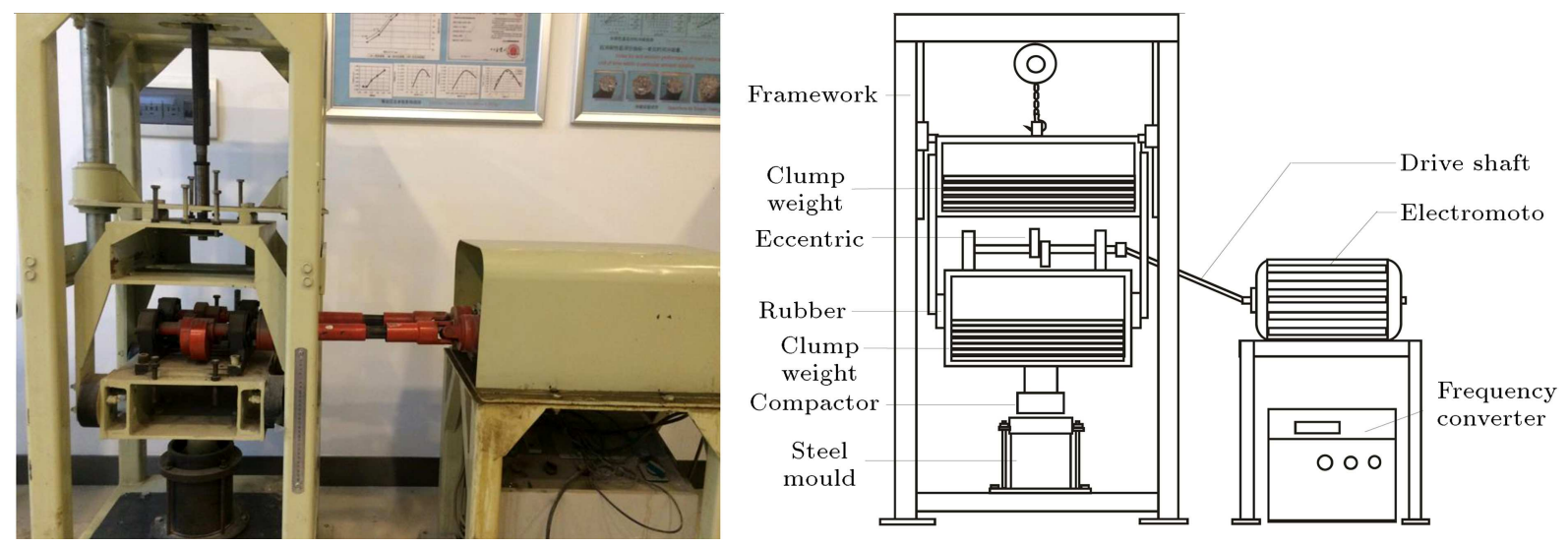

Figure 2. The vibratory compactor and diagram of Vibration Compaction Method (VCM) in laboratory.

$$
A=0.25 \pi D^{2},
$$

where UCS is the unconfined compressive strength (MPa), $P_{u}$ is the maximum pressure value $(\mathrm{N}), A$ is the sectional area of measured sample $\left(\mathrm{mm}^{2}\right)$, and $D$ is the diameter of cylinder.

Also, the samples were measured by tensile splitting test (T0806-1994); Tensile Splitting Strength (TSS) could be achieved by Eq. (3).

$$
\operatorname{TSS}=\frac{2 P_{t}}{\pi D h^{\prime}}\left(\sin 2 \alpha-\frac{a}{D}\right)
$$

where TSS is the tensile splitting strength (MPa), $a$ is the width of the depression bar $(\mathrm{mm}), \alpha$ is the central angle of half depression bar $\left(^{\circ}\right), P_{t}$ is the maximum pressure value in tensile splitting test $(\mathrm{N})$, and $h^{\prime}$ is the height of sample after being immersed in water.

Additionally, the Compressive Resilience Modulus (CRM) was detected with T0808-1994 method. In CRM test, cylindrical samples $(\varnothing=150 \mathrm{~mm}, h=$ $150 \mathrm{~mm}$ ) were used and the compressive resilience modulus was calculated with Eq. (4).

$$
E=p \times h / l,
$$

where $E$ is the compressive resilience modulus (MPa), $p$ is the unit pressure during CRM test $(N), h$ is the height of sample, and $l$ is the rebound deformation of cylinder $(\mathrm{mm})$.

During measurements, in order to reduce the experimental errors, 9 samples were produced for each group and the average value was adopted, whose error was less than $10 \%$. To observe the performance evolution of cement stabilized aggregates, specimens were measured at 7, 28,90, and $180 \mathrm{~d}$.

Specimens $(100 \times 100 \times 400 \mathrm{~mm}$ under OWCs conditions) for Drying Shrinkage Strain (DSS) measurement were cured in the chamber at $40^{\circ} \mathrm{C}$ to accelerate cement hydration. Before measurement, CSA surface had to be polished for the strain gages setting. Here, the operation process was based on the standards of T0854-2009 in JTG E51-2009 [15]. In this study, the shrinkage strain was calculated as follows:

$$
\varepsilon=\frac{\Delta \lambda_{14}}{\lambda}
$$

where $\varepsilon$ is the drying shrinkage strain, $\Delta \lambda_{14}$ is the length change of the specimen at 14 days, and $\lambda$ is the original length of the specimen.

\section{Experimental result of engineering performances}

\subsection{Relationship of moisture and mixtures' dry densities}

The relation of drying density and water content in CSAs was measured according to T0804-1994 in JTG E51-2009 [15]. The results are plotted in Figure 3, in which parabolas are also shown with their quadratic polynomials. Based on maximum density method, the peak plots on the curves are the maximum density point and optimum water content in construction. The OWC and MDD of CSAs with increase in WRA are detailed in Table 1.

Figure 4(a) presents the OWCs of the six groups of mixtures. It is obvious that the OWCs slightly decreased with increase in WRA content, e.g., the slope of the line in Figure 4(a) is -0.1155 . This result means that water content in application would be significantly reduced, e.g., the initial water-cement ratio of control mixture was 1.12 , which then decreased to 1.03 ( $8.1 \%$ reduction by $0.5 \%$ WRA), $0.99(10.7 \%$

\begin{tabular}{|c|c|c|c|c|c|c|}
\hline WRA content $(\%)$ & 0 & 0.5 & 1.0 & 1.5 & 2.0 & 2.5 \\
\hline OWC (\%) & 5.03 & 4.62 & 4.49 & 4.39 & 4.65 & 4.62 \\
\hline $\operatorname{MDD}\left(\mathrm{g} / \mathrm{cm}^{\mathbf{3}}\right)$ & 2.19 & 2.26 & 2.26 & 2.36 & 2.28 & 2.35 \\
\hline
\end{tabular}

Table 1. Water Reducer Agent (WRA) effect on Optimum Water Content (OWC) and Maximum Dry Density (MDD) of cement stabilized aggregates. 


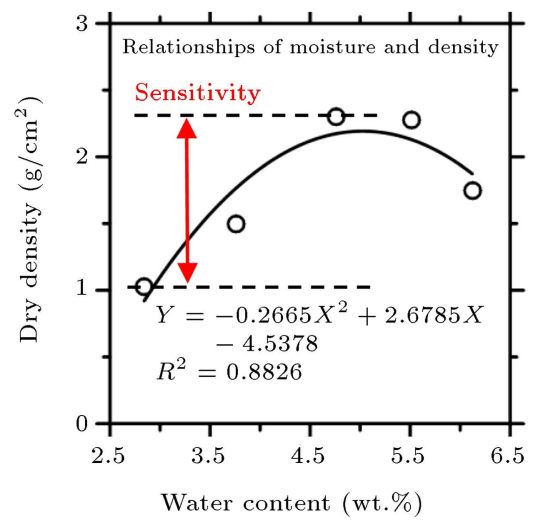

(a)

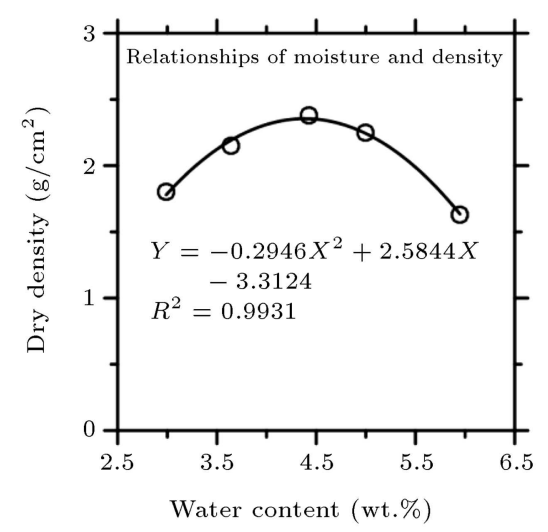

(d)

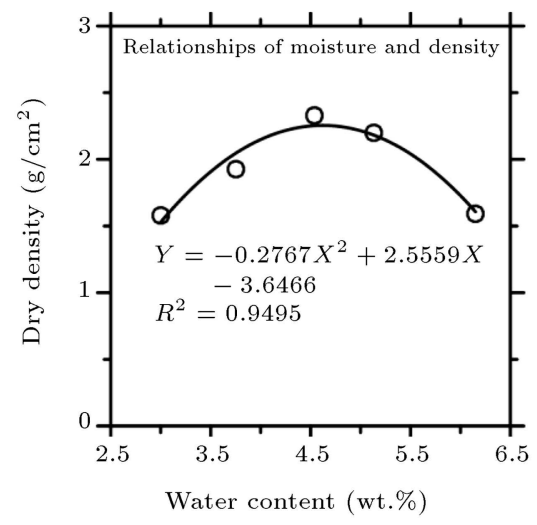

(b)

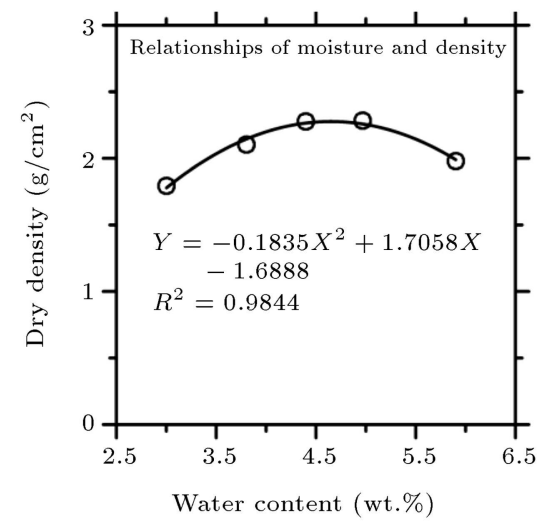

(e)

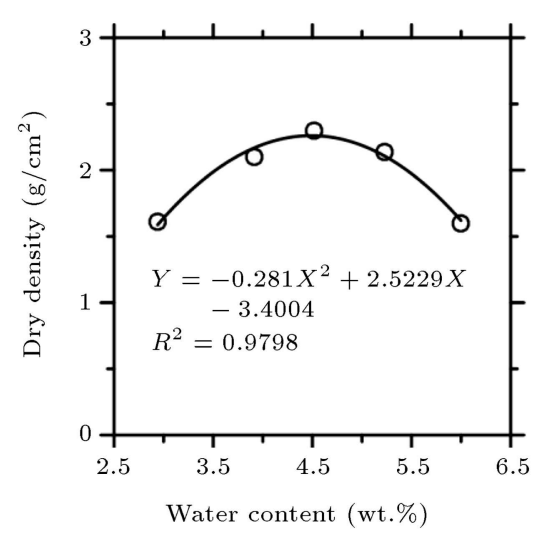

(c)

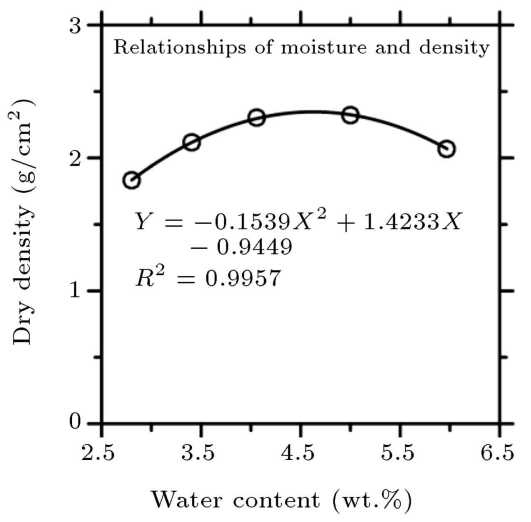

(f)

Figure 3. Moisture-density relationships of cement stabilized aggregate mixtures, while the water reducing agent utilized from (a) to (f) is $0 \%, 0.5 \%, 1.0 \%, 1.5 \%, 2.0 \%$, and $2.5 \%$ of cement binder weight.

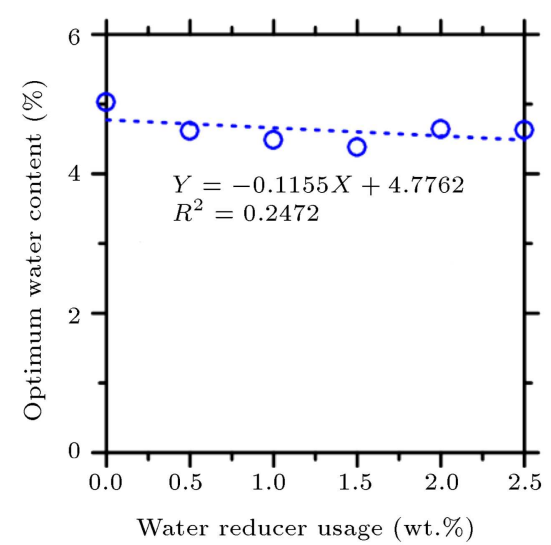

(a)

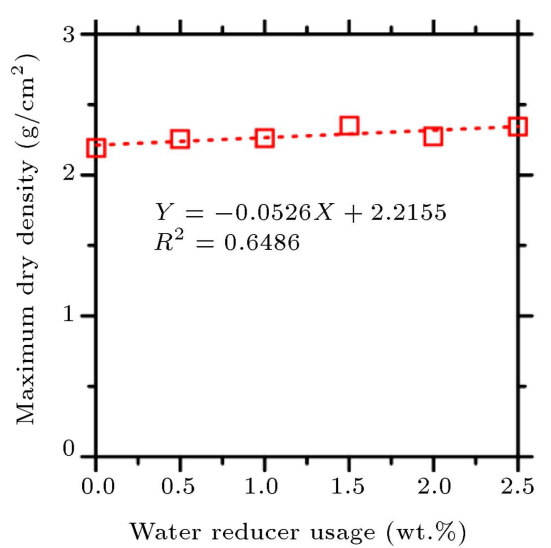

(b)

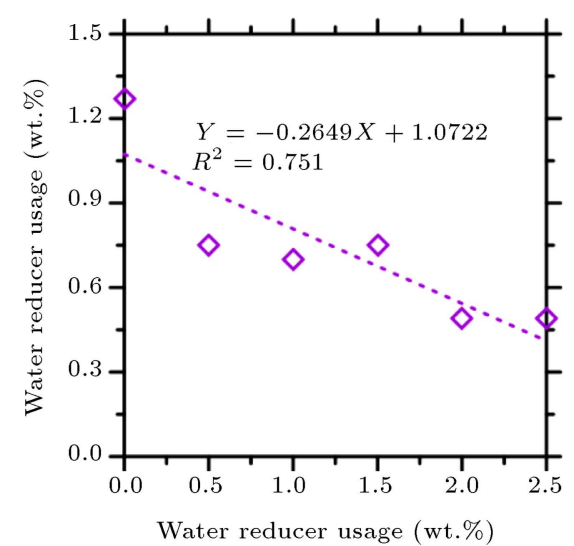

(c)

Figure 4. Water reducing agent effects on optimum water content and mixture density in application: (a) Optimum water content, (b) corresponding density, and (c) moisture sensitivity of mixtures in construction.

reduction by $1.0 \%$ WRA), and 0.97 (12.7\% reduction by $1.5 \%$ WRA). Even the OWCs of the mixtures with 2.0 and $2.5 \%$ WRAs were still lower than that of the control mixture. As believed [7], less drying shrinkage would be caused by low water content in CSAs, which will be discussed below.

The addition of water reducing agent also brings another advantage: enhancement of the maximum drying density of CSAs, as demonstrated in Figure 4(b). Generally, increase in dry density in this case brings at least two benefits:

i) Good integrality and homogeneity of semirigid material blocks. As courses or base 
courses, cement stabilized aggregates have to bear vehicle loadings, mainly. Integrality and homogeneity are significantly linked with the loading bearing capacity, i.e., compressive strength and flexural strength;

ii) Better compaction capacity in applications. All samples in this study were compacted in the same condition, namely, with the same compaction energy. This means that the CSA with a higher dry density could be compacted more easily than the control. In this case (with higher density), the particles of aggregate, cement, and some clay are in closer contact with each other. Thus, during the real application, especially during the vibratory rolling procedure, the CSAs with higher densities could be compacted much more densely; as a result, their mechanical properties would be better.

The data in Figure 3 also provide another characteristic of mixtures. The sensitivity of density to water content was reduced by the addition of water reducing agent, as plotted in Figure 4(c). As known, there are great differences between laboratory compaction and field compaction of CSAs, because it is difficult, in field, to achieve the same quality (i.e., integrality and homogeneity) of CSAs blocks as in laboratory. Thus, the real water content in micro-regions could not be the same as designed (i.e., optimum water content). Water content sensitivity is defined as the delta value between maximum density and minimum density, as shown in Figure 3, where low index (delta density) means that better integrative and homogeneous semirigid block would be achieved concerning the real water content changing in micro-regions. Hence, Figure 4(c) shows that water reducer also benefits the construction quality control in applications.

\subsection{Mechanical behaviors}

Tensile Splitting Strength (TSS) and Unconfined Compressive Strength (UCS) are plotted in Figure 5. The mechanical behaviors (TSS and UCS) of CSAs show an increasing trend over WRAs addition. However, it is hard to say, based on the current data in this study, that the increase in mechanical behaviors, no matter TSS or UCS, is directly caused by the addition of water reducing agent, because the mechanical behavior of CSAs is tightly related to the mixture density [16]. Also, Figure 4(b) reveals the improvement of CSAs dry density by WRAs. Thus, two factors may contribute to the mechanical enhancement:

i) Water-cement ratio was reduced by WRAs. As a result, defects in hydrated cement paste caused by evaporation of free water were reduced. There was very little cement $(4.5 \%)$ in mixtures; thus, little changes in binder might bring great improvement in whole blocks;

ii) Density of CSAs was improved by WRAs. As stated above, better density will ensure the integrality and homogeneity of semi-rigid materials, while interlocking of aggregate particles with skeleton structures mainly provides embedded squeeze forces.

The latter factor seems more reasonable, because little changes in cement binder in CSAs may not bring great variation due to its rare amount. However, the dry density of CSAs is believed to have more influences on mechanical behaviors than water-cement ratio has [11].

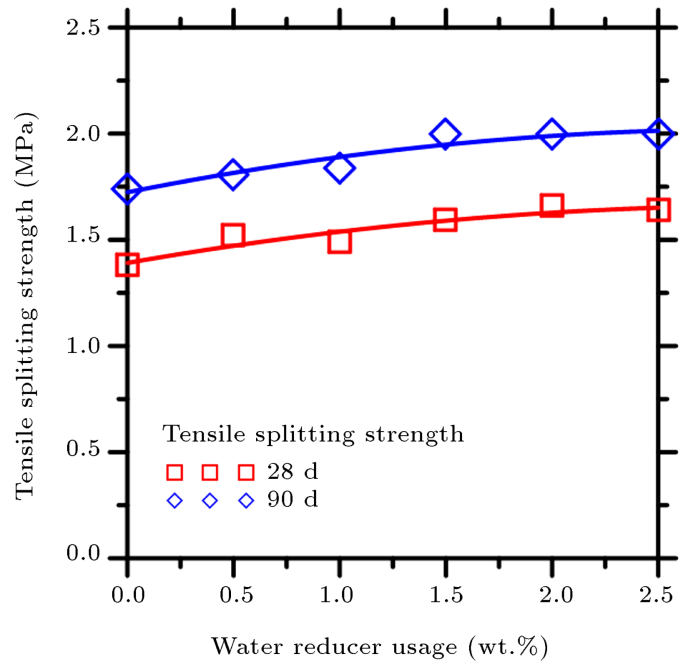

(a)

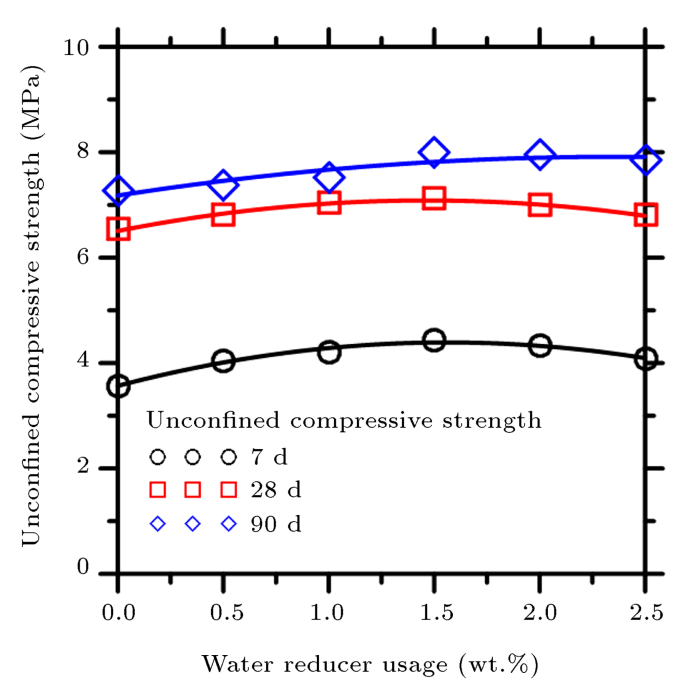

(b)

Figure 5. Relationships of mechanical behaviors and water reducing agent usage in cement stabilized aggregate base course mixtures: (a) Tensile splitting strength and (b) unconfined compressive strength. 


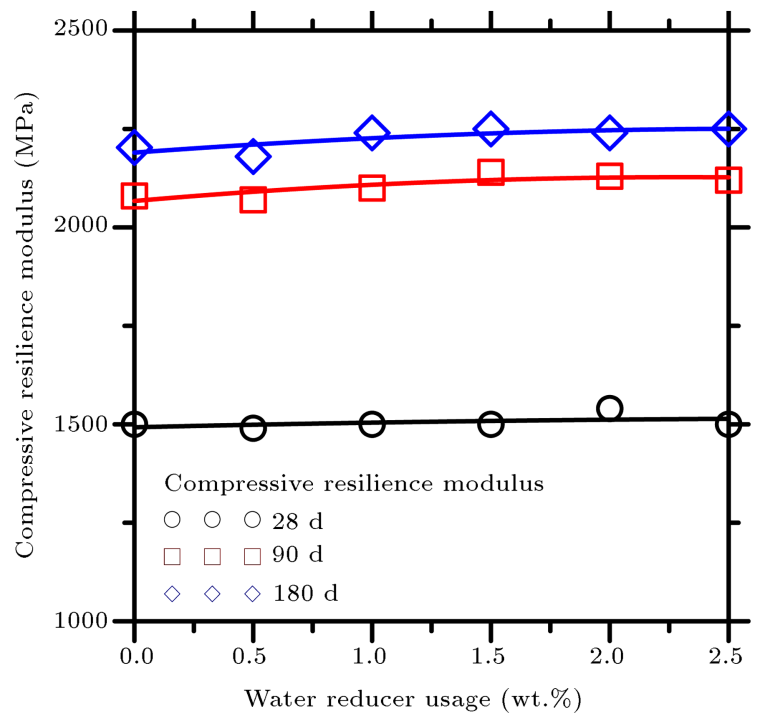

Figure 6. Water reducing agent effects on the compressive resilience modulus of cement stabilized aggregate mixtures.

\subsection{Compressive resilience modulus}

CRM is significantly linked with the shrinkage stress and higher CRMs will produce higher stress under the same shrinking level in hydration. The Compressive Resilience Modulus (CRM) of CSAs at 28, 90, and $180 \mathrm{~d}$ is detailed in Figure 6. It seems that WRA has little effect on the CRM beyond 28 days, but makes a slight increase in CRM at 90 and 180 days. The low CRM at early ages $(28 \mathrm{~d})$ can bring other benefits to CSAs, because shrinkage mainly occurs at early ages. Thus, based on the above data, this result suggests that WRAs will enhance mixture density, reduce water usage, and have a slight influence on compressive resilience modulus, even at early ages; meanwhile, the slight influence might be contributed by the densification function. Compared with the compressive strength and flexural strength, the influence of WRAs on CRMs is low.

\subsection{Drying shrinkage strain}

As mentioned in Sections 3.1 and 3.3, the main goal of this study is to prevent the drying shrinkage of CSAs, thus to reduce the risk of bottom-up cracks of asphalt pavement surface. Therefore, the strains during drying shrinkage were measured as detailed in Section 2.3. The drying shrinkage strain is plotted in Figure 7 versus water reducing agent usage. As desired, the drying shrinkage strain decreased with increase in water reducer usage in CSAs mixtures.

Based on Hooke's law, briefly, the shrinkage stress is equal to modulus times shrinkage strain. Thus, the conclusion, based on the results observed in Figure 7, can be that the stress produced by drying shrinkage will be potentially reduced when the mechanical behavior of matrix is improved. As a result, as stated in

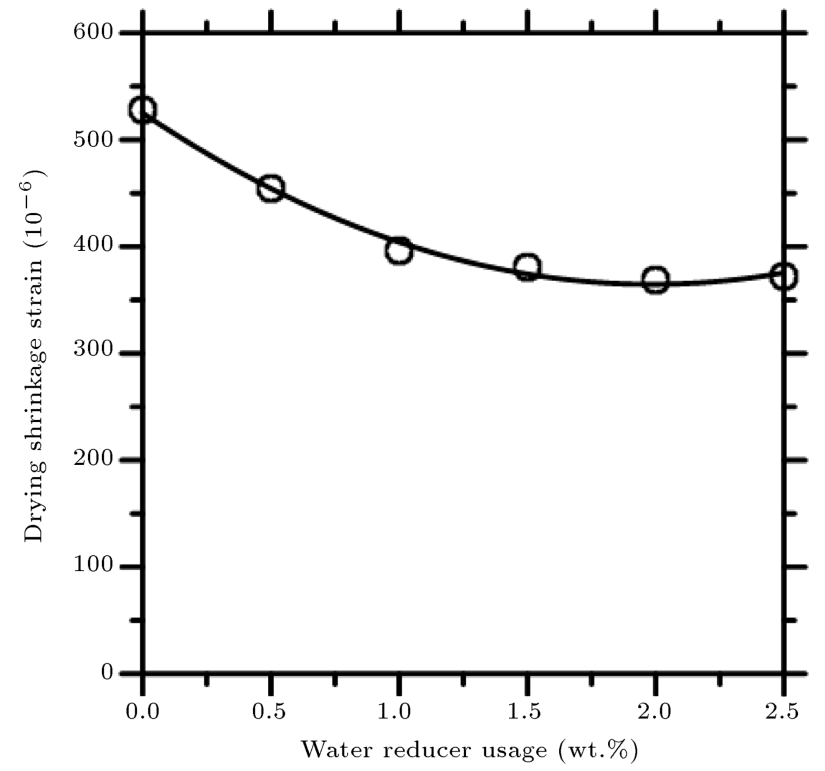

Figure 7. Drying shrinkage strain in cement stabilized aggregate mixtures affected by water reducing agent.

Figure 5, the capacity to prevent cracking in cement stabilized aggregates base course will be significantly increased leading to the risk reduction of bottomup cracking of asphalt pavement surface. As well, the strains measurement shows that a great amount $(>2.0 \%)$ of WRAs may not work well to reduce the drying shrinkage in CSAs.

\subsection{Linking of unconfined compressive strength to tensile splitting strength and compressive resilience modulus}

The relationship between unconfined compressive strength and tensile splitting strength, whose slope is defined as flexural compression ratio that can be used to evaluate the anti-cracking performance, is presented in Figure 8(a). The trend provides two pieces of important information:

i) Tensile splitting strength of CSAs increases with the improvement of unconfined compressive strength. This trend can be confirmed in most of the cement-based composites. Thus, unconfined compressive strength can be measured to estimate the tensile splitting strength in the same special condition. In addition, improvement of the UCS can be an efficient solution to improve the tensile splitting strength;

ii) TSS-UCS ratio of CSAs is stable $(k=$ 0.4186) in this case. However, it should be noted that this trend does not mean the flexural compression ratios of all types of CSAs are stable. It works only under the limitation of this study, that is, with the same mixture gradation for incorporating Water Reducing Agents (WRAs). Flexural compression ratio of cement-based material indicates 


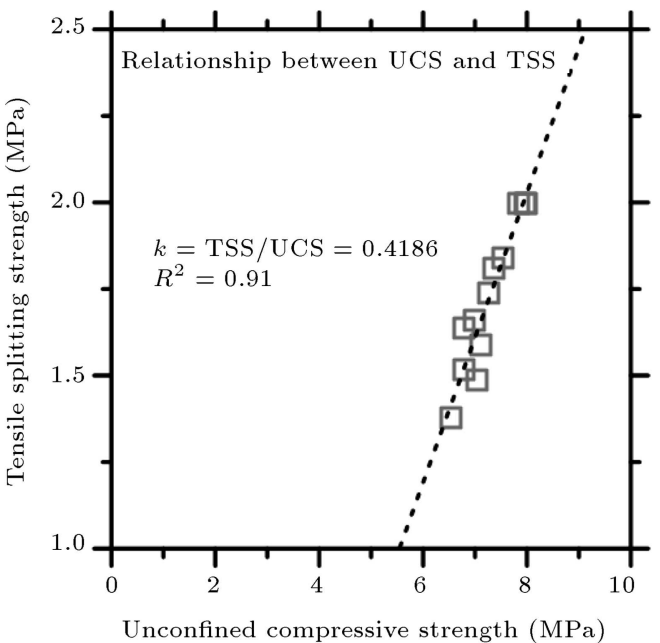

(a)

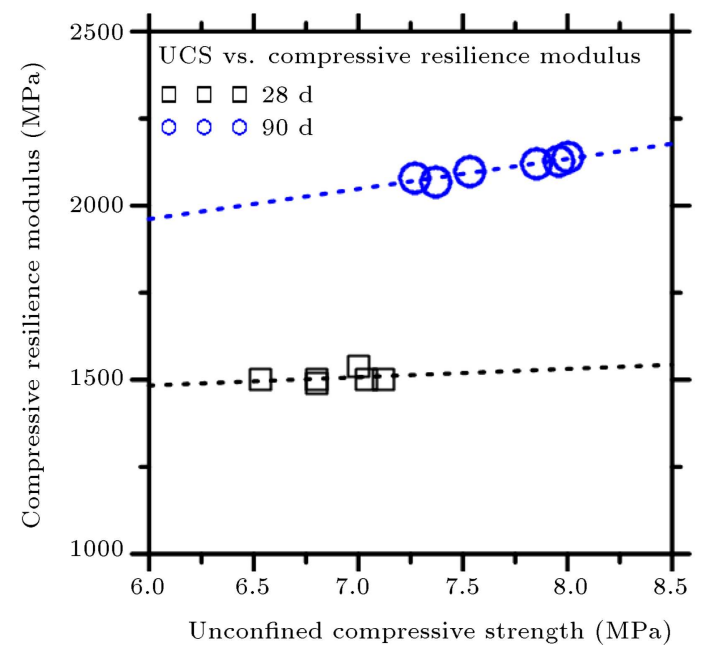

(b)

Figure 8. Relationships between mechanical behaviors of cement stabilized aggregate mixtures: (a) Unconfined compressive strength and tensile splitting strength and (b) unconfined compressive strength and compressive resilience modulus.

the anti-cracking performance under loading stress. The stable flexural compression ratio shows that the anti-cracking performance of CSAs will not be greatly changed incorporated in WRAs.

Figure 8(b) shows the relationship between UCS and CRM in CSAs. It is clear that there is a good linear relationship between unconfined compressive strength and compressive resilience modulus at not only 28 days, but also 90 days. The CRMs were kept stable beyond 28 days after the addition of water reducing agent, but there was a slight improvement beyond 90 days. This two results are in good agreement with the observation in Figure 6.

\section{Roles of water reducing agent in cement stabilized aggregate base course}

The roles of Water Reducing Agents (WRAs) in Cement Stabilized Aggregates (CSAs) are absolutely similar to those in cement concrete. Figure 9 presents the working mechanism of WRAs in CSAs. CSAs are usually used as the base or subbase course (named semi-rigid material) with little amount of cement binders (nearly 4 5 wt.\%) and sufficient water content (5 6 wt.\%) compared with the water needed for hydration $(w / c=0.42)$ [17]. Different from Portland cement concretes, CSAs have to face severe problems, specifically the drying shrinkage at early ages, bringing cracks to CSAs blocks and, further, producing bottomup cracking.

As shown in Figure 9, moisture evaporation in cement paste in CSAs will occur in hardening process, no matter what mixture structure it is [7]. Due to the effects of dispersion, electrostatic repulsion, and lubrication of the water reducing agent, the water wrapped in cement flocculation structure was released $[1,2]$, which led to more uniform distribution of water in the mixture. Thereby, the reduced friction-force was generated by aggregate particles during compacting, moving, and rotating. As a result, the aggregate particles could move smoothly and be compacted more easily (Figure 3). Also, the dry density increased (Figure 4(b)). Finally, the mechanical behaviors improved (Figures 5 and 6 ) and the drying shrinkage (Figure 7 ) was reduced by the reduction in optimum water content (Figure 4(a)).

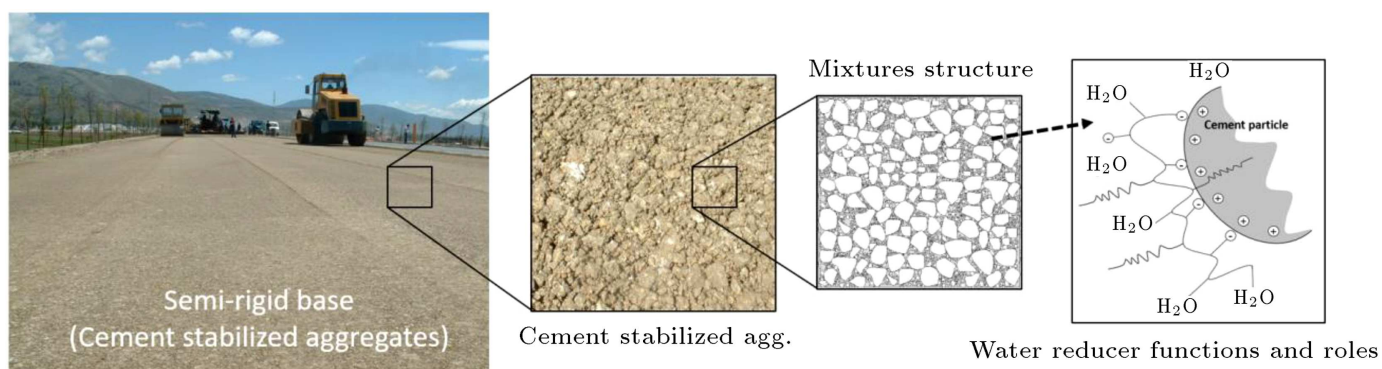

Figure 9. Roles of Water Reducing Agents (WRAs) in Cement Stabilized Aggregates (CSAs). 


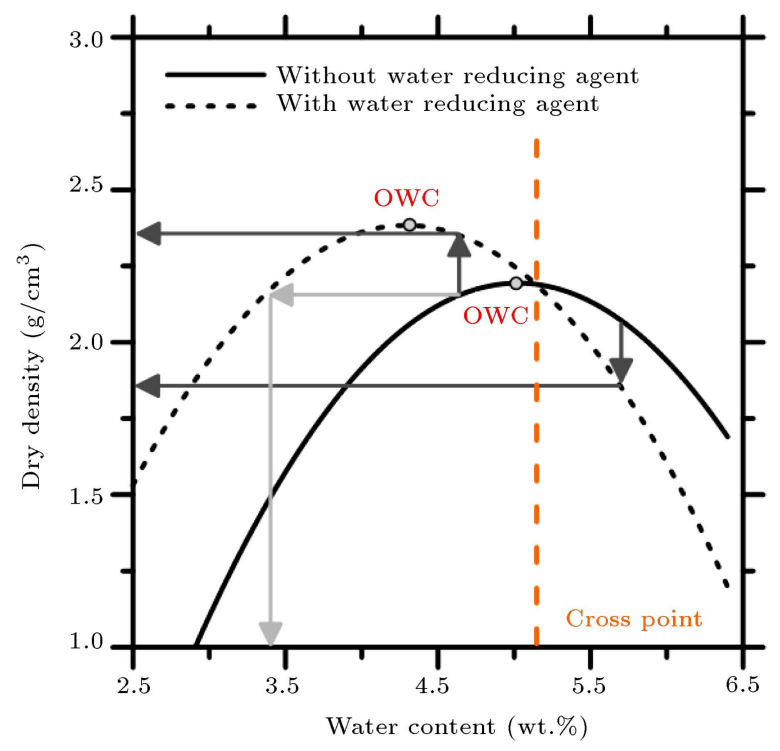

Figure 10. Schematic diagram of the function of water reducing agents in cement stabilized aggregate mixtures. The solid line is the control sample without water reducing agent and the dashed line is cement stabilized aggregate containing $1.5 \%$ water reducing agent (OWC: Optimum Water Content).

The significances of this study could be summarized in the schematic diagram (Figure 10), presenting the density-water curve of CSAs incorporated in Water Reducing Agent (WRA). Based on the maximum density method, the deductions on different sides of the crossing point of curves are opposite. Take the left side, for instance; basically, the dashed line (containing water reducing agent) is above the solid line (control sample without water reducing agent). Some important conclusions are provided in the following. After addition of water reducing agents:

i) Mechanical behaviors of CSAs will be improved, due to the enhancement of dry density with the same mixture proportion;

ii) The (optimum) water content will be decreased to achieve the same mixture's dry density, leading to reduction in drying shrinkage strain and improvement of the sustainable properties;

iii) The compaction energy will be lowered, to achieve the same dry density with unchanged mixture proportion, which also improves the damage resistance caused by heterogeneous composites, benefiting the quality control in application.

\section{Conclusions}

Desired functions or roles of water reducing agent utilized in cement stabilized aggregates were achieved for engineering performance in this study. Water reducing agent in cement stabilized aggregates decreased the optimum water content, improved the maximum dry density, and benefited the sensitivity of water content during compaction. As a result, the unconfined compressive strength and tensile splitting strength were improved, while slight effects on compressive resilience modulus were observed. In summary, water reducing agent in cement stabilized aggregates had at least three basic benefits: improving the mechanical behaviors, reducing the optimum water content, and promoting the quality control.

\section{Acknowledgement}

The authors gratefully acknowledge the financial support of the National Science \& Technology Pillar Program during the Twelfth Five-year Plan Period of China (No. 2014BAG05B04), and Fundamental Research Funds from the Central Universities (No. 2014G3213004).

\section{References}

1. Taylor, H.F., Cement Chemistry, 2nd Ed., Thomas Telford (1997).

2. Young, J.F., Mindess, S., and Darwin, D., Concrete, Prentice Hall (2002).

3. Bentz, D.P., Peltz, M.A., and Winpigler, J. "Earlyage properties of cement-based materials. II: Influence of water-to-cement ratio", J. Mater. Civ. Eng., 21, pp. 512-517 (2009).

4. Li, V.C., Wang, S., and Wu, C. "Tensile strainhardening behavior of polyvinyl alcohol engineered cementitious composite (PVA-ECC)", ACI Mater. J.Am. Concr. Inst., 98, pp. 483-492 (2001).

5. Mehta, P.K. and Monteiro, P.J., Concrete: Microstructure, Properties, and Materials, 2rd Ed., McGraw-Hill, New York (2006).

6. Xuan, D.X., Houben, L.J.M., Molenaar, A.A.A., and Shui, Z.H. "Mechanical properties of cement-treated aggregate material-a review", Mater. Des., 33, pp. 496-502 (2012)

7. Sha, A. and Hu, L. "Structural characteristics of semirigid base course material", China J. Highw. Transp., 24, pp. 1-5 (2008).

8. Chakrabarti, S. and Kodikara, J. "Direct tensile failure of cementitiously stabilized crushed rock materials", Can. Geotech. J., 44, pp. 231-240 (2007).

9. Halsted, G.E., Luhr, D.R., and Adaska, W.S. "Guide to Cement-Treated Base (CTB)", Portland Cement Association, Skokie, USA (2006).

10. Jitsangiam, P. and Nikraz, H. "Mechanical behaviour of hydrated cement treated crushed rock base (HCTCRB)", Aust. Geomech., 42, pp. 133-143 (2007).

11. Huang, Yubin, Lv, Weimin, Xu, Jianda and We, Ming "Effect of water reducing agent on the physical and mechanical properties of cement stabilized crushed rock", J. Build. Mater., 8, pp. 311-315(2005). 
12. Ministry of Transportation, JTG D50-2006, Specifications for Design of Highway Asphalt Pavement, Ministry of Transportation, Beijing, China (2006).

13. ACI Committee 327, ACI 327R-14, Guide to RollerCompacted Concrete Pavements, American Concrete Institute, Farmington Hills, MI (2015).

14. Mardani-Aghabaglou, A. and Ramyar, K. "Mechanical properties of high-volume fly ash roller compacted concrete designed by maximum density method", Constr. Build. Mater., 38, pp. 356-364 (2013).

15. Ministry of Transportation, JTG E51-2009, Test Methods of Materials Stabilized with Inorganic Binders for Highway Engineering, Ministry of Transportation, Beijing, China (2009).

16. Luo, Jiaguo, Liang, Xiaoxia and Liu, Yanyan. "Analysis of differences in compactedness of cement stabilized gravel by formation methods", Technol. Highw. Transp., pp. 8-11 (2010) (in Chinese).

17. Powers, T.C. and Brownyard, T.L. "Studies of the physical properties of hardened Portland cement paste", ACI J. Proc., ACI (1946).

\section{Biographies}

Liqun Hu, PhD, is Professor and Director of the Institute of Highway Engineering, School of Highway, Chang'an University, Xi'an, PR China. He received his MS and PhD degrees in Road and Railway Engineering from Chang'an University in 2000 and 2004, respectively. His research interests include road materials, pavement structure, eco-friendly pavement, road construction quality control, and pavement detection techniques.

Zhuangzhuang Liu, $\mathrm{PhD}$, is Asistant Professor in the School of Highway, Chang'an University. He received his $\mathrm{BS}, \mathrm{MS}$, and $\mathrm{PhD}$ degrees from Chang'an University in 2010, 2013, and 2016, respectively. His research interests are related to the structuresmaterials-functions problems of pavements in special regions. His current study includes building materials in cold climates, winter road maintenance, low-carbon footprint building materials, etc.

Aimin Sha, PhD, is Professor of Highway and Railway Engineering in the School of Highway, Vice-President of Chang'an University, and director of the Key Lab of Special Region Highway Engineering, MOE, PR China. He received his BS and MS degrees from Xi'an Highway University (Chang'an University), in 1985 and 1987, respectively, and $\mathrm{PhD}$ degree from Kharkov National Automobile and Highway University in 1996. His main research interests are focused on road material, pavement design theory, construction quality control, eco-friendly pavement, and "Green" transportation. 